\title{
Relações entre o clima e o progresso da ferrugem asiática (Phakopsora pachyrhizi) em duas micro-regiões do Estado do Paraná
}

\section{Relationship between climate and the progress of the asian soybean rust (Phakopsora pachyrhizi) in two micro-regions of Paraná State}

\author{
Rodrigo Y. Tsukahara ${ }^{1}$; Marceli Hikishima²; Marcelo G. Canteri ${ }^{3 *}$
}

\begin{abstract}
Resumo
O trabalho objetivou estudar, em condições de campo, a influência do clima no progresso da ferrugem da soja (Phakopsora pachyrhizi). Dois ensaios foram conduzidos na safra 2005/2006, um na região de Castro e outro em Arapoti, Paraná. Dividiu-se a epidemia em três períodos: semeadura até primeiros sintomas da doença, do início da doença até severidade de $20 \%$ e severidade de $20 \%$ até severidade máxima. Os sintomas da ferrugem apareceram em Castro aos 78 dias e em Arapoti aos 82 dias após a semeadura. A maior duração do período de molhamento foliar - Dpm (18 horas) foi observada em Castro. No segundo período da epidemia, Arapoti apresentou taxa aparente de infecção-r $(0,18)$, maior do que observado em Castro $(0,12)$. Durante mesmo período foram observados maiores valores de precipitação e maior índice de número de dias de chuva (Indc) quando comparados à Castro. No período final, em Arapoti obteve-se severidade final de 99,9\% e em Castro 96\%. Observou-se relação entre Dpm com o aparecimento dos primeiros sintomas e também relação entre dados de precipitação e Indc com o progresso da epidemia. As condições ambientais foram mais favoráveis à doença em Arapoti, onde foi observado maior valor da AACPDp $(38,2)$ e menos favoráveis para Castro $(30,4)$.
\end{abstract}

Palavras-chave: Epidemia, molhamento foliar, precipitação, severidade da doença, Glycine max

\begin{abstract}
The objective of the work was to study the influence of the climate on the progress of the soybean rust (Phakopsora pachyrhizi) under field conditions. Two assays were carried out during the 2005/2006 season in Castro and Arapoti regions, Paraná. The epidemic was divided in three periods: sowing until first symptoms of disease; beginning of the disease until severity of $20 \%$ and severity of $20 \%$ until maximum severity. The rust symptoms occurred in Castro at 78 days and in Arapoti at 82 days after the sowing. The biggest duration of leaf wetness period - Dpm (18 hours) was observed in Castro. During the second period of the epidemic, Arapoti presented apparent infection rate-r $(0.18)$, higher than observed in Castro (0.12). During same period were observed greater rainfall values and greater index of number of days of rain - Indr compared with Castro. The final disease severity was $99.9 \%$ in Arapoti and $96 \%$ in Castro 96\%. It was observed a relation between Dpm with the appearance of the first symptoms and was also observed and relation between precipitation data and Indc with the progress of the epidemic. The ambient conditions had been more favorable to the disease in Arapoti, where bigger value of AACPDp (38.2) was observed and less favorable for Castro (30.4).
\end{abstract}

Key words: Epidemic, leaf wetness, rainfall, disease severity, Glycine max

1 Engenheiro Agrônomo Pesquisador Agrometeorologia - Fundação ABC

2 Engenheira Agrônoma, Mestre em Agronomia. - Universidade Estadual de Londrina

3 Engenheiro Agrônomo, Professor Dr. ,Adjunto, Departamento de Agronomia da Universidade Estadual de Londrina. e-mail: canteri@uel.br

* Autor para correspondência 


\section{Introdução}

A Ferrugem asiática da soja é causada pelo fungo Phakopsora pachyrhizi Syd. \& P. Syd. (JULIATTI et al., 2005). O primeiro relato da doença foi em 1902, no Japão. A doença, desde então, causa grandes perdas em diversos países do continente asiático (BROMFIELD, 1984). Na década de 90 foi relatada pela primeira vez no Hawaí e na África (KAWUKI; ADIPALA; TUKAMUHABWA, 2003). Em 2001, na América do Sul, foram observadas epidemias em campos de produção de soja safrinha e em soja "guaxa" em lavouras no Paraguai e no Brasil (YORINORI; PAIVA, 2002; YORINORI et al., 2005). Até a safra 2005/06 praticamente todas as áreas produtoras de soja no Brasil apresentaram focos da doença.

A rápida expansão e o grande potencial de perdas fazem da ferrugem asiática uma das mais importantes doenças da cultura da soja (YORINORI et al., 2005). O fungo, muito agressivo, pode causar rápido amarelecimento e queda prematura de folhas, causando danos na formação das vagens e enchimento de grãos (YANG et al., 1991). Reduções na produtividade foram relatadas na Tailândia (10$40 \%$ ), na China (10-50\%) e em Taiwan (23-90\%) (TCHANZ, 1999). No Brasil as perdas de produção podem atingir $70 \%$ em áreas não controladas (YORINORI et al., 2005).

A doença tornou-se epidêmica recentemente no país, portanto as medidas de controle ainda estão sendo definidas. Na falta de cultivares resistentes, o uso de fungicidas é a melhor medida de controle. A determinação das condições climáticas favoráveis ao desenvolvimento da ferrugem da soja, considerando as cultivares utilizadas no Brasil e as épocas de semeadura, pode fornecer subsídios importantes para a tomada de decisão referente ao momento ideal para se fazer o controle químico.

Resultados de literatura demonstram o efeito de variáveis climáticas, principalmente temperatura e molhamento foliar sobre a capacidade dos fungos infectarem e provocarem doenças na parte aérea da soja (REIS, 2004). A presença do molhamento é fundamental para a ocorrência da doença, já que a presença ou ausência da água livre na superfície foliar determina à possibilidade de germinação dos esporos e conseqüentemente a ocorrência da infecção. Marchetti, Melching e Bromfield (1976) demonstraram o efeito da temperatura e duração do período de molhamento na germinação e infecção por uredosporos de P. pachyrhizi. Este trabalho mostrou que o fungo foi capaz de germinar entre as temperaturas de $7^{\circ}$ e $28^{\circ} \mathrm{C}$, com faixa ótima de $15^{\circ}$ a $25^{\circ} \mathrm{C}$. Infecções ocorreram com temperaturas entre $20^{\circ} \mathrm{C}$ e $25^{\circ} \mathrm{C}$ e 6 horas de duração de molhamento, sendo que taxas de infecções máximas ocorreram entre 10 a $12 \mathrm{~h}$ de molhamento.

Estudo realizado em diferentes regiões de Uganda sobre as perdas de produção atribuídas à ferrugem asiática da soja mostrou que os graus de severidade da doença foram significamente diferentes para cada região do estudo. As menores perdas foram observadas em regiões com temperaturas mais baixas $\left(12,9^{\circ} \mathrm{C}\right)$ e as maiores em regiões mais quentes (KAWUKI; ADIPALA; TUKAMUHABWA, 2003). Del Ponte et al. (2006) estudaram a associação de variáveis climáticas com a severidade final da ferrugem da soja de várias epidemias de diferentes regiões do Brasil e observaram que a precipitação apresenta forte correlação com a severidade final da doença.

Considerando a importância da integração de medidas de controle para a ferrugem asiática da soja, este trabalho teve como objetivo estudar, em condições de campo, a influência do clima no progresso da ferrugem asiática da soja em duas diferentes regiões do estado do Paraná.

\section{Material e Métodos}

Dois ensaios foram conduzidos em campos experimentais da Fundação ABC, localizados na região dos Campos Gerais do Paraná, entre $24^{\circ} \mathrm{e}$ $26^{\circ}$ Sul de latitude e $49^{\circ}$ e $51^{\circ}$ Oeste de longitude. Um ensaio foi conduzido em Arapoti e outro em 
Castro, durante a safra 2005/2006. De acordo com a classificação climática de Köeppen, o tipo climático predominante no município de Castro é o $\mathrm{Cfb}$, enquanto Arapoti apresenta o tipo climático Cfa.

Foi utilizada a variedade de soja BRS 154, considerada muito suscetível à ferrugem (EMPRESA BRASILEIRA DE PESQUISA AGROPECUÁRIA, 2004). Os experimentos foram montados em blocos ao acaso com 4 repetições e foram conduzidos de acordo com as recomendações técnicas de produção de soja para a região. As parcelas experimentais consistiam de 7 linhas de $5 \mathrm{~m}$ cada com espaçamento entre linhas de $0,4 \mathrm{~m}$. Somente as 5 linhas centrais foram usadas para coleta de dados.

As avaliações de severidade da ferrugem foram realizadas após constatação dos primeiros sintomas (incidência superior a 5\%), em intervalos de 7 dias, estendendo-se até a senescência das folhas, entre os estádios fenológicos $\mathrm{R}_{6}$ e $\mathrm{R}_{7}$. A amostragem consistiu na retirada de 10 trifólios/parcela sendo 4 do terço inferior, 3 do terço médio e 3 do terço superior da planta. Para determinação da porcentagem de severidade da doença foi utilizada a escala diagramática proposta por Godoy, Koga e Canteri (2006).

As variáveis climáticas: temperatura em ${ }^{\circ} \mathrm{C}(\mathrm{T})$, precipitação pluvial em mm (Prec.) e duração do período de molhamento foliar em horas (Dpm) foram coletadas por estações agrometeorológicas localizadas próximas aos campos experimentais de cada região. Com base nos dados de precipitação, determinou-se a variável número de dias de chuva $(\mathrm{Ndc})$. Foi considerado um dia de chuva aquele com precipitação igual ou superior a $2 \mathrm{~mm}$ entre as 00:00 e 23:59 horas. Com os valores diários de clima registrados em cada avaliação, calculou-se a média das variáveis temperatura, Dpm, precipitação e Ndc para os três períodos e para toda a epidemia. Foi calculado o índice de número de dias de chuva (Indc), dividindo-se o Ndc pela duração em dias de cada período.
Os dados médios de severidade da doença foram utilizados para traçar as curvas de progresso da doença. Com base nestas curvas, dividiu-se a epidemia em três períodos: do plantio até a severidade inicial, da severidade inicial até aproximadamente $20 \%$ de severidade e da severidade de $20 \%$ até a severidade final da doença.

Calculou-se a área abaixo da curva de progresso da doença (AACPD) e a área abaixo da curva de progresso da doença padronizada (AACPDp) para toda a epidemia. Para cada período foi calculado o número de dias da sua duração e a taxa aparente de infecção (r).

A AACPD foi calculada de acordo com equação apresentada por Campbel e Madden (1990) e a AACPDp foi calculada dividindo-se o valor da AACPD pelo $n^{\circ}$. total de dias da epidemia para cada local do estudo. Para determinar o melhor modelo epidemiológico para o cálculo da taxa aparente de infecção utilizou-se metodologia descrita por Bergamim Filho e Amorim (1995). Os dados de severidade de ferrugem foram analisados buscandose correlação com os dados climáticos observados sob condições de campo.

\section{Resultados e Discussão}

A doença ocorreu nos dois ensaios e a maior ou menor intensidade variou de acordo com as condições climáticas prevalecentes em cada região. A severidade máxima foi de 99,9\% em Arapoti e 96\% em Castro (Figura 1).

O modelo logístico foi o que melhor se ajustou aos dados de severidade da doença para os dois locais, com coeficiente de determinação $\left(\mathrm{R}^{2}\right)$ igual a 0,95 (Arapoti) e 0,98 (Castro) (Tabela 1). Este modelo também foi utilizado por Gastaldi (2005) com dados de severidade da ferrugem da soja. Em função do melhor ajuste, utilizou-se para o cálculo da taxa aparente de infecção a equação $r=(1 / t) *(\ln (x /(1-$ $\mathrm{x}))-\ln (\mathrm{x} 0 /(1-\mathrm{x} 0)))$. 


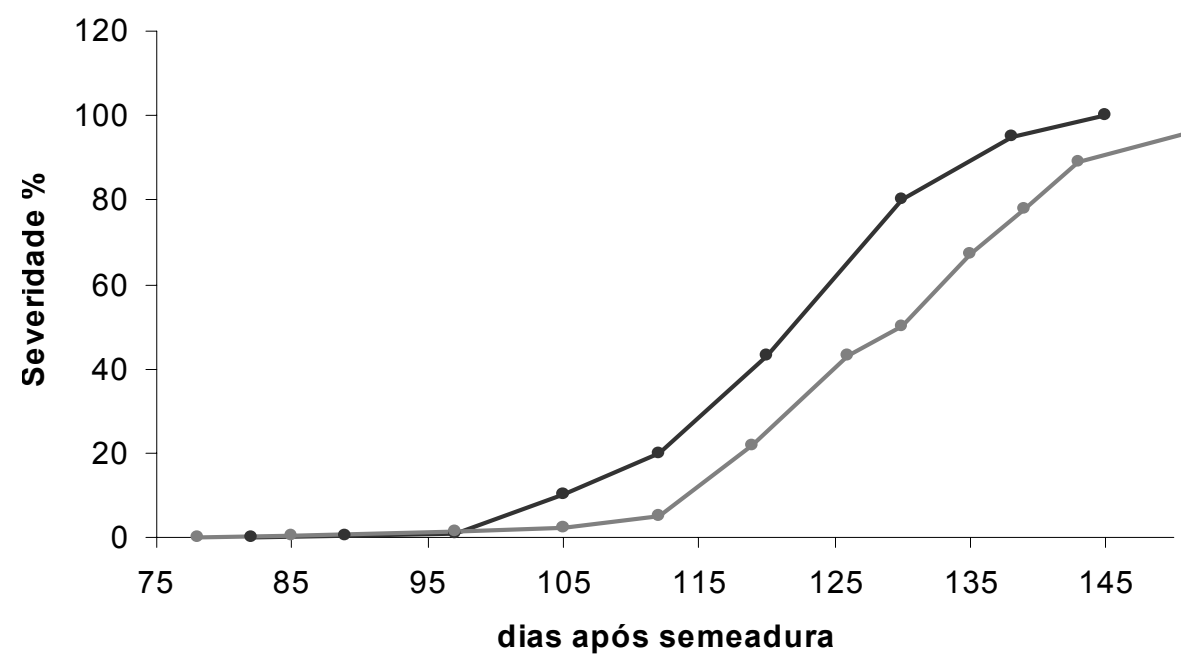

Figura 1. Curvas de progresso da ferrugem asiática da soja (P.pachyrhizi) observadas em Castro e Arapoti na safra 2005/2006.

Tabela 1. Modelos epidemiológicos e coeficientes de determinação $\left(\mathrm{R}^{2}\right)$ ajustados para a curva de progresso da ferrugem asiática da soja (P. pachyrhizi) para dois locais.

\begin{tabular}{lllll}
\hline & & \multicolumn{3}{c}{ Modelos epidemiológicos } \\
\hline Local & Exponencial & Monomolecular & Logístico & Gompertz \\
\hline Castro & 0,95 & 0,73 & 0,98 & 0,9 \\
& $\mathrm{p}<0,0001^{*}$ & $\mathrm{p}=0,0011$ & $\mathrm{p}<0,0001$ & $\mathrm{p}<0,0001$ \\
\multirow{2}{*}{ Arapoti } & 0,88 & 0,68 & 0,95 & 0,83 \\
& $\mathrm{P}=0,0010$ & $\mathrm{p}=0,0113$ & $\mathrm{P}=0,0002$ & $\mathrm{p}=0,0023$ \\
\hline
\end{tabular}

*p $=$ valores de probabilidade de significância

As condições climáticas que favorecem o desenvolvimento da ferrugem da soja são temperaturas entre $15^{\circ} \mathrm{C}$ e $25^{\circ} \mathrm{C}$ e o mínimo de 6 horas de duração do período de molhamento foliar, com ocorrência de severidades máximas entre $10 \mathrm{a}$ 12 horas (MARCHETTI; MELCHING; TUKAMUHABWA, 1976). Sob condições brasileiras, Alves, Furtado e Bergamin (2006), em experimentos conduzidos com isolado P. pachyrhizi obtido no Brasil, quantificaram o efeito da temperatura e da duração do período de molhamento na germinação do fungo. Os resultados obtidos estão de acordo com aqueles obtidos por Marchetti (1976). Ambos os estudos demonstram que a faixa ótima para germinação do patógeno é de $15^{\circ} \mathrm{C}$ a $25^{\circ} \mathrm{C}$ e que o período de molhamento necessário para a infecção tornou-se mais longo em temperaturas desfavoráveis.

Analisando-se o desenvolvimento da ferrugem nas duas regiões (Tabela 2), observou-se que em Castro a severidade inicial da doença ocorreu no estádio fenológico $\mathrm{V}_{10}$ e em Arapoti a doença foi detectada em $\mathrm{R}_{2}$. A análise das variáveis climáticas (Tabela 3), no mesmo período, mostra que as temperaturas de $17,9^{\circ}$ e $18,5^{\circ} \mathrm{C}$ e a duração do período de molhamento (Dpm) de 17,9 e 16,4 horas para Castro e Arapoti, respectivamente, foram favoráveis para a ocorrência da infecção do $P$. pachyrhizi nos dois ensaios. No entanto, o maior valor de Dpm em Castro pode ter 
favorecido o início da epidemia antes de Arapoti, aos 78 dias após a semeadura.

$\mathrm{Na}$ segunda parte da epidemia, ou seja, do início dos sintomas até aproximadamente $20 \%$ de severidade, as condições de Dpm e temperaturas continuaram sendo favoráveis à doença nas duas regiões. Porém, observou-se que em Arapoti a taxa aparente de infecção $(r)$ da doença $(0,18)$ foi superior à observada em Castro $(0,12)$. Isto pode ser explicado pelos maiores valores de precipitação registrados em Arapoti neste período. Resultados semelhantes foram encontrados por Del Ponte et al. (2006) ao estudarem epidemias de ferrugem da soja em várias regiões do Brasil. Os autores encontraram alta correlação da precipitação (95\%) com a severidade final da doença. Tchanz (1982) em estudo realizado em Taiwan sugeriu que o efeito direto da chuva na epidemia de ferrugem da soja pode estar relacionado com a dispersão dos esporos dentro do dossel e desta forma contribui para o rápido desenvolvimento da doença no início da epidemia.

$\mathrm{Na}$ análise da fase final da epidemia, pode-se observar em Arapoti a severidade final foi $99,9 \%$ e a taxa $r$ foi igual a 0,18 . Estes resultados foram superiores aos obtidos em Castro, que teve severidade final de $96 \%$ e taxa $\mathrm{r}$ de 0,14 . Analisandose as condições climáticas no mesmo período para as duas regiões observou-se que além da precipitação, o Indc foi fator crítico para o maior progresso da ferrugem da soja em Arapoti e menor em Castro, confirmando resultados de Del Ponte et al. (2006), ou seja, alta correlação entre número de dias de chuva e severidade final da ferrugem (93\%).

Apesar de se tratar de apenas dois ensaios, podese observar que houve relação entre a duração do período de molhamento com o aparecimento dos primeiros sintomas, e a relação dos dados de precipitação e do Indc com o progresso da epidemia de ferrugem asiática da soja, confirmando trabalhos anteriores realizados em câmaras de crescimento (MARCHETTI; MELCHING, BROMFIELD, 1976) e Alves et al. (2006) e em campo (DEL PONTE et al., 2006).

Estudando todo o período da epidemia e os dados de clima para cada região concluiu-se que as condições ambientais foram mais favoráveis à doença em Arapoti, que teve maior valor da AACPDp (Tabela 2), 38,2, e menos favoráveis para a região de Castro, onde foi observado o menor valor, 30,4.

Tabela 2. Dados da epidemia da ferrugem da soja (P. pachyrhizi) dividida em três períodos e o período total em cada local.

\begin{tabular}{|c|c|c|c|c|c|c|c|c|c|c|c|c|}
\hline \multirow[b]{2}{*}{ Local } & \multicolumn{3}{|c|}{$\begin{array}{c}\text { Semeadura até } \\
\text { severidade inicial }\end{array}$} & \multicolumn{3}{|c|}{$\begin{array}{c}\text { Severidade inicial até } \\
20 \%\end{array}$} & \multicolumn{3}{|c|}{$\begin{array}{c}\text { Severidade de } 20 \% \text { até } \\
\text { a severidade final }\end{array}$} & \multicolumn{3}{|c|}{$\begin{array}{c}\text { Período } \\
\text { Total da Epidemia }\end{array}$} \\
\hline & $\begin{array}{l}\mathrm{N}^{\mathrm{o}} \mathrm{de} \\
\text { dias }\end{array}$ & $\mathrm{EF}^{*}$ & Sev. $\%$ & $\begin{array}{l}\mathrm{N}^{\circ} \text { de } \\
\text { dias }\end{array}$ & $\mathrm{EF}$ & $\begin{array}{l}\text { Taxa } \\
\text { (r) }\end{array}$ & $\begin{array}{l}\mathrm{N}^{\circ} \mathrm{de} \\
\text { dias }\end{array}$ & Sev. $\%$ & $\begin{array}{l}\text { Taxa } \\
\text { (r) }\end{array}$ & $\begin{array}{l}\mathrm{N}^{\circ} \text { de } \\
\text { dias }\end{array}$ & $\mathrm{AACPD}^{* *}$ & AACPDp *** \\
\hline Castro & 78 & V10 & 0,2 & 41 & R5.1 & 0,12 & 32 & 96,0 & 0,14 & 73 & 2406,8 & 30,4 \\
\hline Arapoti & 82 & R2 & 0,1 & 30 & R5.3 & 0,18 & 33 & 99,9 & 0,18 & 63 & 2221,9 & 38,2 \\
\hline
\end{tabular}

Estádio fenológico em que foi observada a severidade para cada período.

** Área abaixo da curva de progresso da doença

*** Área abaixo da curva de progresso da doença padronizada 
Tabela 3. Duração do período de molhamento - Dpm (média diária), temperatura média, índice de número de dias de chuva (INDC) e média diária de precipitação, registrados em cada período (1, 2 e 3$)$ e em toda a epidemia da ferrugem da soja (P. pachyrhizi) para as regiões de Castro e Arapoti.

\begin{tabular}{clllllllllllllllll}
\hline & \multicolumn{4}{c}{ Dpm (horas) } & \multicolumn{4}{c}{ Temperatura $\left(\mathbf{~}^{\circ} \mathbf{C}\right)$} & \multicolumn{4}{c}{ Precipitação (mm) } & \multicolumn{4}{c}{ Indc } \\
Local & $1 *$ & 2 & 3 & Total** & 1 & 2 & 3 & Total & 1 & 2 & 3 & Total & 1 & 2 & 3 & Total \\
\hline Castro & 17,9 & 16,3 & 17,0 & 18,2 & 17,9 & 19,4 & 18,6 & 20,7 & 3,8 & 2,6 & 4,3 & 3,4 & 0,3 & 0,3 & 0,3 & 0,30 \\
Arapoti & 16,4 & 17,7 & 17,1 & 17,6 & 18,5 & 19,6 & 19,1 & 21,5 & 5,2 & 7,3 & 9,7 & 8,5 & 0,3 & 0,3 & 0,5 & 0,40 \\
\hline
\end{tabular}

*Períodos da epidemia: 1 - Semeadura até severidade inicial, 2- Severidade inicial até 20\%, 3 - Severidades de $20 \%$ até a severidade final,

**Total: soma dos valores do início até o fim da epidemia dividido pela sua duração.

\section{Referências}

ALVES, S. A. M.; FURTADO, G. Q.; BERGAMIN, A. Influência das condições climáticas sobre a ferrugem da soja. In: ZAMBOLIM, L. Manejo integrado: ferrugem da soja e doenças quarentenárias dos citros. Viçosa: Suprema, 2006. p.37-59.

BERGAMIN FILHO, A.; AMORIM, L. Curvas de progresso da doença. In: BERGAMIN FILHO, Armando (Org.). Manual de fitopatologia: princípios e conceitos. 3.ed. São Paulo: Ceres, 1995. v.1, p.602-626.

BROMFIELD, K. R. Soybean rust. Saint Paul: American Phytopathological Society, 1984. (Monograph n.11).

CAMPBELL, C. L.; MADDEN, L. V. Introduction to plant disease epidemiology. New York: John Willey, 1990. p.329352.

DEL PONTE, E. M.; GODOY, C. V.; LI, X.; YANG, X. B. Predicting severity of Asian Soybean rust epidemics with empirical rainfall models. Phytopathology, Saint Paul, v.96, n.7,p.797-803, 2006.

EMPRESA BRASILEIRA DE PESQUISA AGROPECUÁRIA - EMBRAPA. Tecnologias de produção de soja: região central do Brasil 2005. Londrina: Embrapa Soja, 2004. p.239.

GASTALDI, L. F. Eficiência de fungicidas e efeito do ambiente na severidade da ferrugem asiática causada por Phakopsora pachyrhizi em soja. 2005. Dissertação (Mestrado em Agronomia) - Universidade Estadual de Londrina, Londrina.

GODOY, C. V.; KOGA, L. J.; CANTERI, M. G. Diagramatic scale for assessment of soybean rust severity. Fitopatologia Brasileira, Brasília, v.31, p.63-68, 2006.

JULIATTI, F. C.; POLIZEL, A. C.; BALARDIN, R. S.; VALE, F. X. R. Ferrugem da soja: epidemiologia e manejo para uma doença reemergente. Revisão Anual de Patologia de Plantas, Passo Fundo, v.13, p.351-395, 2005.
KAWUKI, R. S.; ADIPALA, E.; TUKAMUHABWA, P. Yield loss associated with soya bean rust (Phakopsora pachyrhizi Syd.) in Uganda. Journal of Phythopatology, Berlin, v.151, p.7-12, 2003.

MARCHETTI, M. A.; MELCHING, J. S.; BROMFIELD, K. $\mathrm{R}$. The effects of temperature and dew period on germination and infection by uredospores of Phakopsora pachyrhizi. Phythopatology, Saint Paul, v.66, n.6, p.461463, 1976.

REIS, E. M. Previsão de doenças de plantas. Passo Fundo: UPF, 2004.

TCHANZ, A. T. Soybean rust epidemiology: final report. Shanhau, Taiwan: Asian Vegetable Research and Development Center, 1982.

Soybean rust. In: SINCLAIR, J. B.; BACKMAN, P. A.(Eds.). Compendium of soybean diseases. $3^{\text {th }}$ Saint Paul: The American Phytopathological Society Press, 1999. p.24-26.

YANG, X. B.; TSCHANZ, A. T.; DOWLER, W. M.; WANG, T. C. Development of yield loss models in relation to reductions of components of soybeans infected with Phakopsora pachyrhizi. Phytopathology, Saint Paul, v.81, p.1420-1426, 1991.

YORINORI, J. T.; PAIVA, W. M. Ferrugem da soja: Phakopsora pachyrhizi Sydow. Londrina: Embrapa Soja, 2002. Folder.

YORINORI, J. T.; PAIVA, W. M.; FREDERICK, R. D.; COSTAMILAN, L. M.; BERTAGNOLLI, P. F.; HARTMAN, G. L.; GODOY, C. V.; NUNES JUNIOR, J. Epidemics of soybean rust (Phakopsora pachyrhizi) in Brazil and Paraguay from 2001 to 2003. Plant Disease, Saint Paul, v.89, p.675-677, 2005. 